\title{
Current occurence of intraspinal intradural and extradural communicating branches in the spinal canal
}

\author{
Matejcik $\mathrm{V}^{1}$, Haviarova $\mathrm{Z}^{2}$, Kuruc $\mathrm{R}^{3}$, Steno $\mathrm{J}^{1}$ \\ Department of Neurosurgery, Faculty of Medicine, University Hospital, ComeniusUniversity, \\ Bratislava, Slovakia.matejcik@pobox.sk
}

\begin{abstract}
THE AIM of this work is to point out the intraspinal anatomical current occurrence interconnections between intradural and extradural nerve roots and their possible participation in radiculopathy.

METHODS: The anatomical study was performed in 43 cadavers with a mean age of 53.7. All intradural and extradural rami communicantes between nerve roots were excised and examined histologically for the presence or absence of nervous tissue.

RESULTS: Anatomical preparations revealed intradural and extradural rami communicantes in 9 cases $(20.9 \%)$, mostly in the cervical region in 5 cases and by plexus formation variations in 5 cases. Multiple extradural rami communicantes were observed in 6 cases $(13.95 \%)$, including the simultaneous occurrence of multiple intradural and extradural ones in 5 cases (11.6\%).

CONCLUSIONS: This study allowed us to identify and describe unpublished intraspinal current occurrence intradural-extradural rami communicantes of nerve roots and their interrelationships throughout the spinal canal with their potential influence on the clinical picture (Tab. 1, Fig. 4, Ref. 25). Text in PDF www.elis.sk. KEY WORDS: intraspinal nerve roots, intradural nerve roots, extradural nerve roots, nerve roots variations.
\end{abstract}

\section{Introduction}

To our knowledge, no study has reported current occurens interconnections between intradural and extradural nerve roots in the cervical, thoracic, and lumbosacral region in reference to a normal, prefixed, or postfixed type of brachial and lumbosacral plexuses.

Most of the papers on the intraspinal variations of nerve roots dealt with extradural anatomical variations of lumbosacral nerve roots $(1-17)$.

The present study was undertaken to determine if there is any relationship between the level and concentration of intraduralextradural root interconnections with their potential influence on the clinical picture.

\section{Materials and methods}

The anatomical study was carried out in 43 fresh cadavers without congenital or detected abnormalities, tumour diseases, orthopaedic deformities and spinal operations within 24 hours

${ }^{1}$ Department of Neurosurgery, Faculty of Medicine, University Hospital, Comenius University, Bratislava, Slovakia, ${ }^{2}$ Institute of Anatomy, Faculty of medicine, Comenius University, Bratislava, Slovakia, and ${ }^{3}$ Institute of Pathological Anatomy, Health Care of Surveillance Authority, Bratislava, Slovakia

Address for correspondence: V. Matejcik, MD, PhD, Department of Neurosurgery, Faculty of Medicine, University Hospital, Comenius University, Limbova 5, SK-833 05 Bratislava, Slovakia.

Phone: +421.2.59542532, Fax: +421.2.59543532 from the death. The study included 32 men $(74.4 \%)$ aged 30 to 75 years and 11 women $(25.6 \%)$ aged 45 to 77 years. The subjects had died from a violent death, most often in car accidents, when the spine had not been damaged. The study was conducted with approval with the ethics committee.

In the prone position, we separated paravertebral muscles from processus spinosi and laminas on both sides from the cervicocranial transition to the sacrum. Processus spinosi were removed using bone punches and Stryker's saw. Laminas on both sides, as well as parts of articular projections, were removed with the Kerisson rounger. Such "roofing off" allowed the direct visualization of the spinal canal without damaging the spinal cord and nerve roots. A wide laminectomy from cervico-cranial transition to the sacrum revealed the whole spinal canal to examine each cervical, thoracic, lumbar, and sacral nerve root from its protrusion out of the spinal cord to its exit from the spinal canal through the foramen intervertebrale and hiatus sacralis. Subsequently, we made a longitudinal incision of the dura and we removed it entirely from the spine and nerve roots. The nerve roots were cut distally from the spinal ganglion to allow direct visualization of the spinal cord, conus medullaris, and spinal nerve roots. The exposed segments of the spinal cord and nerve roots were examined, monitored and reviewed, including a detailed examination of the intradural and extradural rami communicantes.

The type of the plexus was defined by subtracting from the root $\mathrm{C} 2$. Specification of the type of plexus was carried out on the basis of the formation of intradural and extradural roots. 


\section{Results}

In 9 cases $(20.9 \%)$, current occurrence extradural and intradural rami communicantes between the nerve roots were observed (Fig. 1, Tab. 1). Mostly in cervical region 5 cases. Extradural anastomosis occurred in the spinal canal before its emergence from the spinal foramen. The anastomosis occurred at the preganglionic level about $1 \mathrm{~cm}$ outside the dura sac.

Multiple extradural rami communicantes were observed in 6 cases (13.95\%) (Fig. 2), including the simultaneous occurrence of multiple intradural and extradural ones in 5 cases (11.6\%). In the cervical region in 3 cases (Fig. 3 ) and in 2 cases in the lumbosacral region. They occurred more frequently by plexus formation variations ( 5 cases). Rami communicantes were mostly - in 6 cases - unilateral. The histological examination confirmed the neural tissue (Fig. 4).

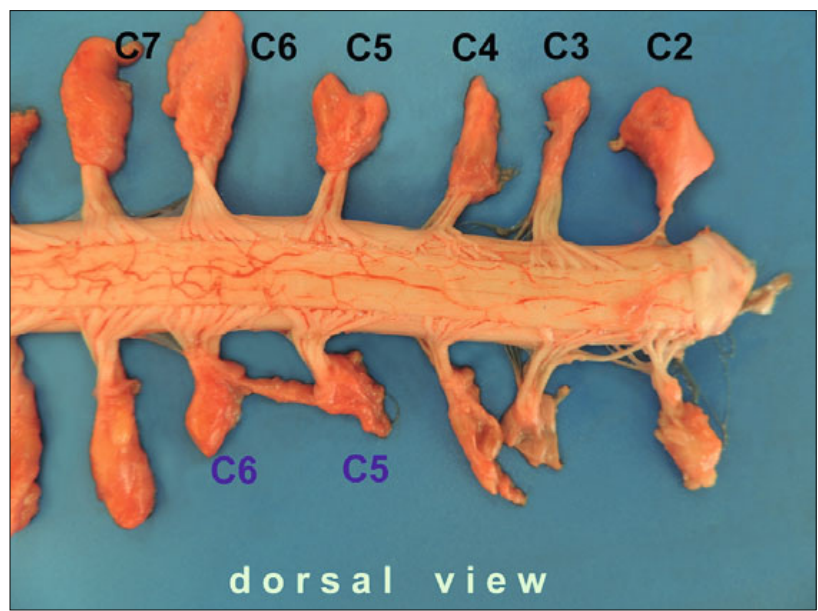

Fig. 1. Dorsal view, intradural ramus communicans between the roots C2-C3 dx. Extradural ramus communicans between the roots C5C6 dx.

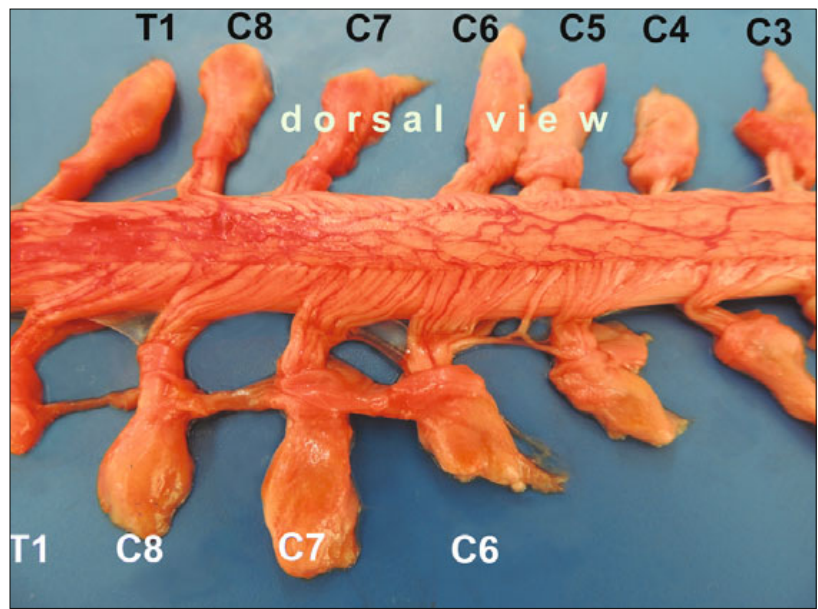

Fig. 2. Dorsal view, intradural ramus communicans between the roots C5-C6 dx. Extradural rami communicantes between the roots $\mathrm{C6}$ C7-C8-T1 dx.

\section{Discussion}

Most of the papers on the intraspinal variations of nerve roots dealt with extradural anatomical variations of lumbosacral nerve roots $(1-17)$. They revealed the extradural rami communicantes ranging from $1 \%$ to $25 \%$ of cases. In our study, it was in 2 cases $(4.6 \%)$.

Comparing our anatomical findings with previous results of other authors $(5,10,11,14)$, it appears that a percentage rate was lower, and the types of extradural variations were partially different.

To our knowledge, no study has reported current occurence between intradural and extradural communicating branches between nerve roots in the cervical, thoracic, and lumbosacral region in reference to a normal, prefixed, or postfixed type of brachial and lumbosacral plexuses.

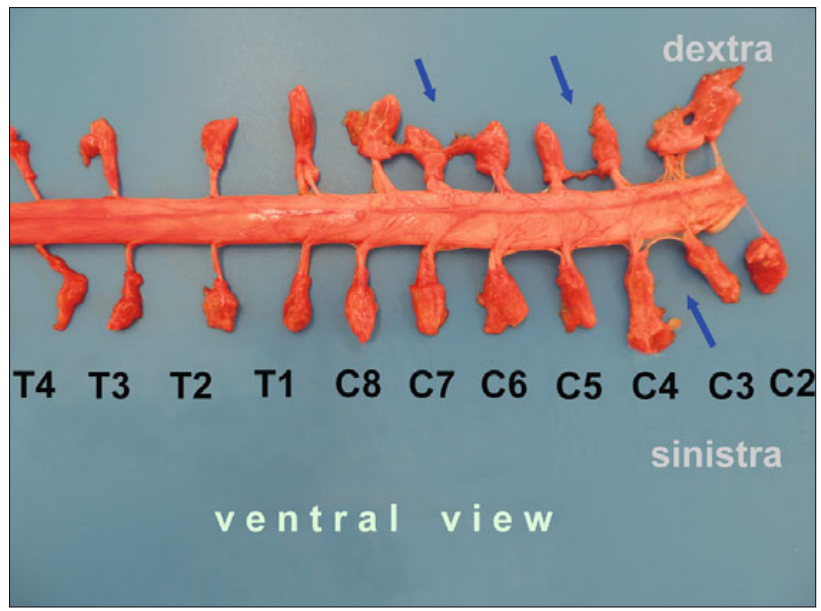

Fig. 3. Ventral view, intradural ramus communicans between the roots $\mathrm{C} 3-\mathrm{C} 4$ sin. Extradural rami communicantes between the roots $\mathrm{C} 4-\mathrm{C} 5$ dx and C6-C7-C8 dx.

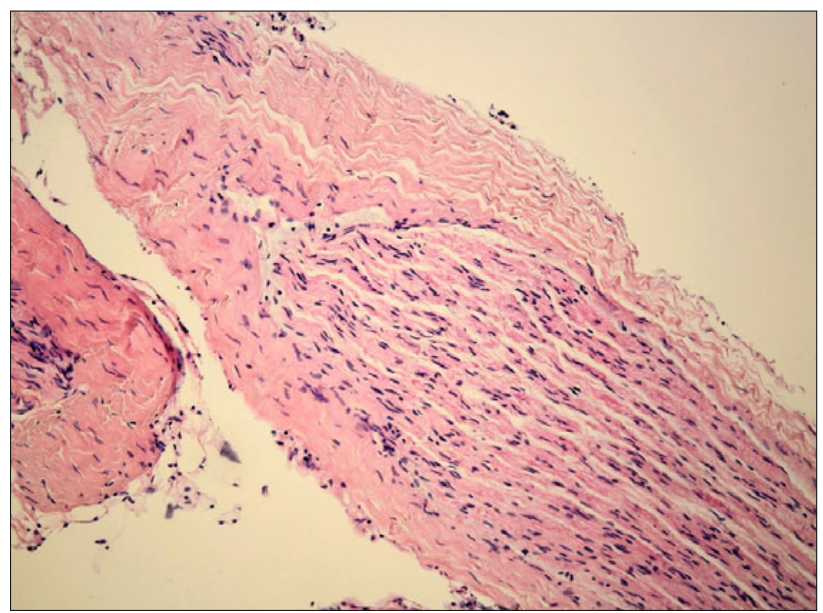

Fig. 4. Longitudinal section of the nerve with perineurium, no inflammation, fibrosis, 200x HE. 


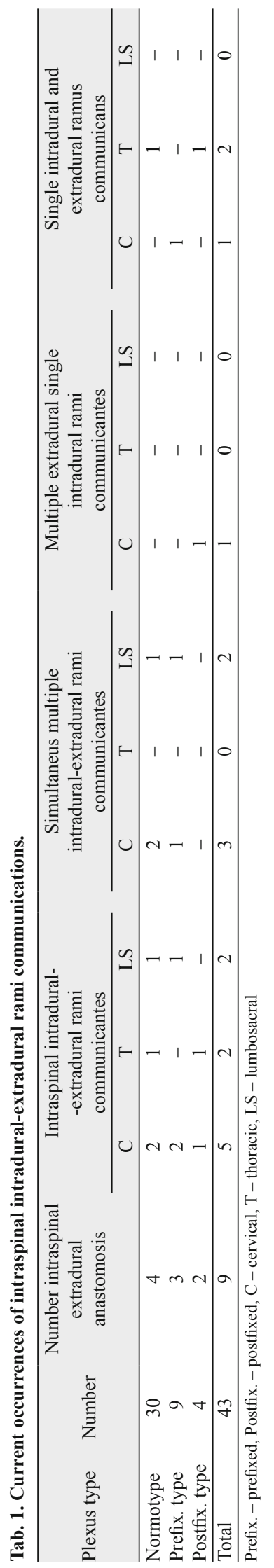

Current occurrence extradural and intradural rami communicantes between the nerve roots were observed in 9 cases $(20.9 \%)$.

Multiple extradural rami communicantes were observed in 6 cases $(13.95 \%)$, including the simultaneous occurrence of multiple intradural and extradural ones in 5 cases $(11.6 \%)$. In the cervical region in 3 cases and in 2 cases in the lumbosacral region. They occurred more frequently -5 cases by the plexus formation variations. Rami communicantes were mostly - in 6 cases - unilateral.

Interneural interconnections may cloud clinical interaction (1, 18, 19).

Embryologic evidence can account for the frequent occurrence of intradural variations. The aetiology of this abnormalities variations is unknown. One hypotesis is the defect of the nerve roots migrations during the first four weeks of embryonic development $(20,21)$.

Symptoms of radiculopathy may manifest intraspinal variations of nerve roots even in cases of the absence of pressure on nerve roots $(5,6,9,22)$. Some papers are based on surgical findings (23); others are based on anatomical studies $(9,12)$. Their incidence ranges from $1.3 \%$ found during the operation (6) to $2-6.7 \%$ detected by imaging methods before surgery $(9,11,16,22)$, and from $8.5 \%$ to $30 \%$ during the study of cadavers $(6,22)$.

They can be the cause of failure in operations of discs (11).

Variations themselves can cause pain. The spinal cord is mobile during normal flexion and extension. Therefore, larger traction forces may be produced with variations in nerve roots, as well as with normal movements of the spinal column (24).

Stretch-induced nerve root injury may be related to changes in the length of the spinal canal and in the length of the nerve root. The perineurium and endoneurium have considerable mechanical strength and serve to protect neural tissues against mechanical forces. However, the intrathecal nerve roots do not have such a protective sheath $(19,25)$. Excessive flexion of the torso during variations surgical procedures may be one of the risk factors for injury of the tethered roots in the presence of intrathecal pathologies (1). Therefore, the current occurrence intraspinal intradural and extradural communicating branches between nerve roots are vulnerable to mechanical stretch, including operative manoeuvres and trauma.

Our study is affected by some factors such as strong regional focus, and a small number of cadavers. This limitation affects the interpretation of our data quality, and the ability to generalise our findings.

\section{Conclusion}

Anatomical preparations revealed a higher incidence of current occurence intraspinal intradural and extradural communicating branches mainly by the plexus formation variations and between cervical roots.

\section{References}

1. Arslan M, Cömert A, Açar HI et al. Lumbosacral intrathecal nerve roots: an anatomical study. Acta Neurochir 2011; 153 (7): 1435-1442.

2. Tubbs RS, El-Zammar D, Loukas M, Cömert A, Cohen-Gadol AA. Intradural cervical root adjacent interconnections in the normal, prefixed, and postfixed brachial plexus. J Neurosurg Spine 2009; 11 (4): 413-416.

3. Marzo JM, Simmons EH, Kallen F. Intradural connections between adjacent cervical spinal roots. Spine (Phila Pa 1976) 1987; 12 (10): 964-968.

4. Moriishi J, Otani K, Tanaka K, Inoue S. The intersegmental anastomoses between spinal nerve roots. Anat Rec 1989; 224 (1): 110-116.

5. Boden SD, Davis DO, Dina TS, Patronas NJ, Wiesel SW. Abnormal magneticresonance scans of the lumbar spine in asymptomatic subjects. A prospective investigation. J Bone Joint Surg Am 1990; 72 (3): 403-408.

6. Burke SM, Safain MG, Kryzanski J, Riesenburger RI. Nerve roots anomalies: implications for transforaminal lumbar interbody fusion surgery and a review of the Neidre and Macnab classification system. Neurosurg Focus 2013; 35 (2): E9.

7. Chotigavanich C, Sawangnatra S. Anomalies of the lumosacral nerve roots. An anatomic investigation. Clin Orhop Relat Res 1992; (278): 46-50.

8. Haijiao W, Koti M, Smith FW, Wardlaw D. Diagnosis of lumbosacral nerve roots anomalies by magnetic resonance imaging. J Spinal Disord 2001; 14 (2): 143-149.

9. Kadish LJ, Simmons EH. Anomalies of the lumbosacral nerve roots. An anatomical investigation and myelographic study. J Bone Joint Surg Br 1984; 66 (3): 411-416.

10. Kikuchi S, Hasue M, Nishiyama K, Ito T. Anatomic and clinical studies of radicular symptoms. Spine (Phila Pa 1976) 1984; 9 (1): 23-30.

11. Neidre A, MacNab I. Anomalies of the lumbosacral nerve roots. Review of 16 cases and classification. Spine (Phila Pa 1976) 1983; 8 (3): 294-299. 


\section{$621-624$}

12. Postacchini F, Urso S, Ferro L. Lumbosacral nerve-root anomalies. J Bone Joint Surg Am 1982; 64 (5): 721-729.

13. Rask MR. Anomalous lumbosacral nerve roots associated with spondylolisthesis.Surg Neurol 1977; 8 (2): 139-140.

14. Scarff TB, Dallmann DE, Toleikis JR, Bunch WH. Dermatomal evoked potentials in the diagnosis of lumbar root entrapment. Surg Forum 1981; 32: 489-491.

15. Solmaz B, Tatarli N, Ceylan D, Keleș E, Çavdar S. Intradural communications between dorsal rootlets of spinal nerves: their clinical significance. Acta Neurochir (Wien) 2015; 157 (6): 1069-1076.

16. Stambough JL, Balderston RA, Booth RE, Rothman RH. Surgical management of sciatica involving anomalous lumbar nerve roots. J Spinal Disord 1988; 1 (2): 111-114; discussion 114-115.

17. Yilmaz T, Turan Y, Gülșen I, Dalbayrak S. Co-occurence of lumbar spondylolysis and lumbare disc herniation with lumbosacral nerve root anomaly. J Craniovertebr Junction Spine 2014; 5 (2): 99-101.

18. Arslan M, Cömert A, Açar HI et al. Nerve root to lumbar disc relationships at the intervertebral foramen from a surgical viewpoint: An anatomical study. Clin Anat 2012; 25 (2): 218-223.
19. Kitab SA, Miele VJ, Lavelle WF, Benzel EC. Pathoanatomic basis for stretch-induced lumbar nerve root injury with a review of the literature. Neurosurgery 2009; 65 (1): 161-167; discussion 167-168.

20. Marieb EN, Mallat J. Základy embryologie. 62-67. In: Marieb EN, Mallat J (Eds). Anatomie lidského těla. Brno: Computer Press a.s., 2005.

21. O'Rahilly R, Müller F, Meyer DB. The human vertebral column at the end of the embryonic periods proper. 4 . The sacrococcygeal region. $\mathrm{J}$ Anat 1990; 168: 95-111.

22. Bedeschi P, Bonola A. Anomalie di origine, di decorso di lungehezza e di diametro delle radici lombari e loro importanza nella patologia dell'ernia del disco. Reumatismo 1956; 8: 266-280.

23. Goffin J, Plets C. Association of conjoined and anastomosed nerve roots in the lumbar region. A case report. Clin Neurol Neurosurg 1987; 89 (2): 117-120.

24. Transfeld EE, Simons EH. Functional and pathological biomechanics of the spinal cord: an in vivo study. Presented at the International Society for the Study of the Lumbar Spine Meeting, Toronto, June 7, 1982.

25. Hasue M. Pain and the nerve root. An interdisciplinary approach. Spine (Phila Pa 1976) 1993; 18 (14): 2053-2058.

Received June 25, 2019. Accepted July 1, 2019. 